\title{
Estudio de morbilidad y mortalidad por aborto en 36 instituciones de Bolivia, Colombia, Perú y Venezuela
}

\author{
Federación Colombiana de Sociedades \\ de Obstetricia y Ginecología FECOLSOG
}

\author{
Dres. Francisco Pardo, Germán Uriza
}

\begin{abstract}
RESUMEN: "Estudio de morbilidad y mortalidad por aborto en 36 Instituciones de Bolivia, Colombia, Perú y Venezuela". - Objetivo de la Investigación: identificar la participación del Aborto como causa de Morbilidad y Mortalidad Materna en las mujeres de la región.

- Metodología: estudio colaborativo multinacional, prospectivo. descriptivo. Se recolectaron 08.871 casos utilizando un formulario de 36 variables para su procesamiento y análisis. El promedio de edad fue de 27 años, con un porcentaje de analfabetismo bajo (4\%) y en la mitad de las pacientes el embarazo era indeseado y tampoco deseaban ningún tipo adicional al que tenía: el $79 \%$ tenían unión estable y el $70 \%$ no utilizaba ningún método anticonceptivo.

La mitad de los casos cursaban embarazos de 11 semanas ó más, las complicaciones más frecuentes fueron la Sepsis y la hemorragía.

La tasa de mortalidad fue muy alta: (406/100.000) que es el doble de la tasa de mortalidad de la región (270/100.000). La Sepsis fue la complicación más relacionada con la muerte.

El manejo de las complicaciones representa un alto que agrava la situación deficitaria de las Instituciones de Salud en los países de vías de desarrollo.
\end{abstract}

PALABRAS CLAVES: Morbilidad, mortalidad y aborto.

SUMMARY: "Morbidity and mortality study due to abortion in 36 bolivian institutions, Colombia, Perú and Venezuela". - Research Objective: Identify the abortión participation as a cause of maternal mortality in women of the region.

- Methodology: It was a multinational collaborative prospective-descriptive study: 8,871 cases were collected and for this purpose a form of 36 variables for processing and analysis, was used.

- Results: The mean age was of 27 years old, with a low percentage of illiteracy (3\%); half of patients had an unwanted pregnancy and neither wanted an additional one; the $79 \%$ had an stable union and the $70 \%$ did not use a contraceptive method.

Half of the cases had pregnancies of 11 weeks and more and the most frequent complications were sepsis and bleeding.

The mortality rate was very high: $(406 / 100,000)$ which doubles the mortality rate in the region $(270 / 100,000)$. Sepsis was the complication more directly related with death.

The way how to deal with complications represents a high cost, which makes worst the financial situation of the health institutions in the under developed countries.

KEY WORDS: Morbidity, mortality, abortion

\section{Introducción}

La Federación Colombiana de Sociedades de Obstetricia y Ginecología (FECOLSOG), miembro de la Federación Latinoamericana de Sociedades de Obstetricia y Ginecología (FLASOG) y de la Federación Internacional de Ginecología y Obstetricia (FIGO) ha sido la coordinadora de estudios colaborativos multinacionales del Grupo Regional Bolivariano de FLASOG constituido por Bolivia, Colombia, Ecuador, Perú y Venezuela; por problemas de orden interno en el Ecuador este país no ha participado en ninguna de las investigaciones colaborativas del Grupo Regional Bolivariano, por lo cual el presente estudio sobre MORBILIDAD Y MORTALIDAD POR ABORTO se realizó en Bolivia, Colombia, Perú y Venezuela.
Participaron 36 instituciones de cuatro (4) países, cinco (5) de Bolivia, quince (15) de Colombia, seis (6) del Perú y diez (10) de Venezuela y el tiempo de la recolección fue de seis (6) meses del 15 de marzo al 15 de septiembre de 1990. * Ver pág, 297

\section{Antecedentes y justificación}

Aprovechando el interés demostrado por la red de investigadores del Grupo Bolivariano de FLASOG que había realizado un estudio colaborativo multinacional en 1989 en cuatro países, sobre embarazo en adolescentes (1), se propuso realizar un estudio sobre Morbilidad y Mortalidad por Aborto, medio frecuentemente utilizado como solución a un embarazo indeseado. 
La necesidad de contar con información científica y datos estadísticos fidedignos sobre las mujeres que han sufrido un aborto y la morbilidad y mortalidad asociadas a él, ha sido señalada por varios expertos como una herramienta esencial para movilizar la voluntad política de los gobiernos, las instituciones privadas de salud y centros docentes asistenciales, hacia acciones concretas que prevengan las nefastas consecuencias en la salud materna del aborto producido en condiciones de inseguridad.

$\mathrm{El}$ 99\% del medio millón de muertes maternas anuales a nivel mundial, se produce en los países en desarrollo (35.000 para América Latina) y aproximadamente el $50 \%$ de estas muertes se deben al aborto inducido en condiciones de inseguridad (2). Un informe mundial sobre Mortalidad Materna reporta para Latinoamérica una tasa de $270 \times$ 100.000 nacidos vivos, muy superior comparada con la de los países desarrollados (3). Una investigación colaborativa realizada en 25 instituciones colombianas reportó una tasa de mortalidad materna de $232 \times 100.000$ nacidos vivos de las cuales el $50.8 \%$ fueron debidas a aborto que en su mayoría fue séptico (4).

Aun cuando en todos los países de la región existen estudios fragmentarios sobre este problema, no hay hasta el momento una investigación colaborativa multinacional, que utilizando una metodología unificada, permita obtener información que refleje la realidad epidemiológica del aborto en los países que participaron en el estudio.

La Federación Latinoamericana de Sociedades de Obstetricia y Ginecología (FLASOG), organización que agrupa a las sociedades y federaciones científicas de obstetricia y ginecología de todos los países latinoamericanos, tiene establecidos grupos regionales de acuerdo a la localización geográfica de los países miembros. Los cinco (5) países del noreste de Suramérica, Bolivia, Colombia, Ecuador, Perú y Venezuela, constituyen el Grupo Bolivariano de la FLASOG. Este grupo, liderado por la Federación Colombiana de Sociedades de Obstetricia y Ginecología (FECOLSOG), realizó en 1989 un estudio colaborativo sobre embarazo en adolescentes en 21 instituciones de Bolivia, Perú, Colombia y Venezuela, presentado durante el XIII Congreso Latinoamericano de Obstetricia y Ginecología en diciembre de 1990. Por las razones ya expuestas en la introducción, Ecuador no participó en este estudio colaborativo.

La realización de la presente investigación por destacados obstetras y ginecólogos de los cuatro países, que ocupan la triple posición de docentes universitarios, directores de servicios hospitalarios y líderes de opinión en el establecimiento médico y social de cada país, ha permitido la conformación de una red que representa un gran potencial investigativo y docente. Este grupo ha demostrado especial interés en mejorar la salud reproductiva de las mujeres de la región.

Aprovechando esta favorable situación, se propone la realización de una investigación sobre el aborto como causa importante de morbilidad y mortalidad maternas. Se prevé que los resultados de la investigación permitirán la toma de decisiones políticas a nivel gubernamental que tengan un impacto favorable en la situación actual y ayuden a modificar la actitud de indiferencia y rechazo que sobre el aborto existe actualmente a nivel docente y asistencial.

Es un hecho conocido que el número de mujeres con embarazo indeseado sigue siendo muy significativo y tiene relación directa con el aborto como uno de los medios a su alcance para solucionar su situación. En América Latina este procedimiento es ilegal y por lo tanto es realizado en condiciones de inseguridad lo que aumenta los índices de morbilidad y mortalidad por infección y hemorragia.

\section{Propósito y objetivos}

Propósito: Realizar una investigación sobre mortalidad y morbilidad causadas por aborto en las mujeres que consultan a hospitales seleccionados por el Grupo Bolivariano de la FLASOG en cuatro países miembros.

Objetivo general: Identificar la participación del aborto como causa de la morbilidad y mortalidad maternas en las mujeres de la región, con el fin de proponer intervenciones tendientes a mejorar su salud reproductiva.

\section{Objetivos específicos:}

1. Identificar la magnitud del problema de la morbilidad y mortalidad por aborto en una población seleccionada en países del Grupo Bolivariano de FLASOG.

2. Presentar los resultados de la investigación en el XIII Congreso Latinoamericano de Obstetricia y Ginecología en Montevideo (Uruguay) en diciembre de 1990 y proponer estudios similares a los demás grupos regionales de FLASOG.

3. Proponer a las entidades públicas y privadas, responsables de los programas docentes y asistenciales, intervenciones tendientes a mejorar la situación encontrada.

\section{Material y métodos}

Para desarrollar el proyecto se utilizó la red de investigadores del Grupo Regional Bolivariano de FLASOG en cuatro de los cinco países integrantes del grupo siendo la Sociedad de Obstetricia y Ginecología de cada país la responsable de seleccionar el coordinador del estudio en su respectivo país.

Participaron la Sociedad Boliviana de Ginecología y Obstetricia, la Federación Colombiana de Sociedades de Obstetricia y Ginecología, Sociedad Peruana de Obstetricia y Ginecología, Sociedad de Ginecología y Obstetricia de Venezuela.

Entre agosto y septiembre de 1989 se elaboró una propuesta que fue enviada a la agencia donante, que aprobó la donación en diciembre, citándose a una reunión de investigadores para elaborar el formulario con su instructivo y seleccionar las instituciones en las cuales se recolectaría la información en cada país.

La reunión de investigadores se realizó en marzo de 1990 y se seleccionaron 36 instituciones: cinco en Bolivia, quince en Colombia, seis en Perú y diez en Venezuela. La población de la investigación la constituyeron los abortos atendidos en las instituciones participantes del 15 de marzo al 15 de septiembre de 1990.

Los coordinadores nacionales seleccionaron un coordinador institucional, quien fue el responsable de la recolección de la información utilizando el formulario e instructivo diseñados para tal fin (Anexos 1 y 2).

Durante el período de la recolección, los coordinadores supervisaron periódicamente el desarrollo de la misma en las instituciones y el director del estudio y el investigador principal hicieron dos visitas de supervisión a Bolivia, Perú y Venezuela. 
Los formularios diligenciados fueron remitidos a la sede de FECOLSOG y fueron procesados por computador.

El cronograma del estudio tuvo cuatro fases (ver cronograma):

1. Fase de planeación: Comprendió la elaboración de la propuesta, el envío de la misma, elaboración de formularios e instructivo y la reunión de coordinadores nacionales del Grupo Regional Bolivariano de FLASOG.

2. Fase de ejecución: Comprendió la recolección de la información y las visitas de supervisión.

3. Fase de análisis: Comprendió el procesamiento y el análisis de los datos, la elaboración del informe y el envío del resumen al Comité Científico del XIII Congreso Latinoamericano de Ginecología y Obstetricia.

4. Fase de presentación de resultados: Comprendió la preparación del material audiovisual de los gráficos y tablas y su presentación el jueves 6 de diciembre en el XIII Congreso Latinoamericano de Obstetricia y Ginecología en Montevideo.

\section{Resultados}

Durante los seis meses del estudio ocurrieron en las instituciones participantes 14.501 abortos de los cuales se analizaron 8.871 y se eliminaron 5.630 casos, 50 por haber sido mal diligenciados; 4.376 no encuestados en Venezuela; 165 de Bolivia que llegaron fuera de tiempo cuando ya se había procesado la información; 667 casos del Hospital General de Medellín porque el coordinador institucional se retiró cuando llevaba tres meses de recolección y la persona a quien él dejó recomendada para continuar la investigación no cumplió con este compromiso, y 372 del Perú porque en cinco instituciones no se recolectó información durante 2 meses de huelga de los empleados de la salud; sólo en la Maternidad de Lima se recolectó información durante los seis meses proyectados. Estos casos de fuerza mayor impidieron que se analizaran los 14.501 abortos ocurridos en las instituciones participantes de marzo 15 a septiembre 15 de 1990 y así cumplir con la meta mínima de 10.000 casos previstos en el protocolo.

En Bolivia se atendieron 12.382 partos y 948 abortos para una relación aborto-parto de $7.66 \%$ (Figura 1). En Colombia se atendieron 46.012 partos y 4.930 abortos que da una relación aborto-parto de $10.71 \%$ (Figura 2). En Perú se atendieron 16.962 partos y 2.305 abortos para una relación aborto-parto de $13.06 \%$ (Figura 3). En Venezuela se atendieron 38.358 partos y 6.268 abortos para una relación abortoparto de $16.34 \%$ (Figura 4). En todos los países se atendieron 113.714 partos y 14.501 abortos para una relación abortoparto de $12.75 \%$ (Figura 5). Hay una diferencia de 50 casos en el total de abortos que fueron mal diligericiados y que están distribuidos en los 4 países.

Abortos según centro hospitalario por país: Participaron 36 instituciones de cuatro países bolivarianos, 5 de Bolivia, 15 de Colombia, 6 del Perú y 10 de Venezuela. El total de casos analizados fue de 8.871 de los cuales el $48.06 \%$ correspondieron a Colombia, con porcentajes similares para Perú, $21.79 \%$, y Venezuela, $21.33 \%$. El menor porcentaje correspondió a Bolivia con $8.83 \%$ (Tabla 1).

Abortos según fecha de admisión: Los meses que presentaron mayor porcentaje de abortos fueron abril con
Figura 1

PORCENTAJE DE ABORTOS CON RELACION A PARTOS (BOLIVIA)

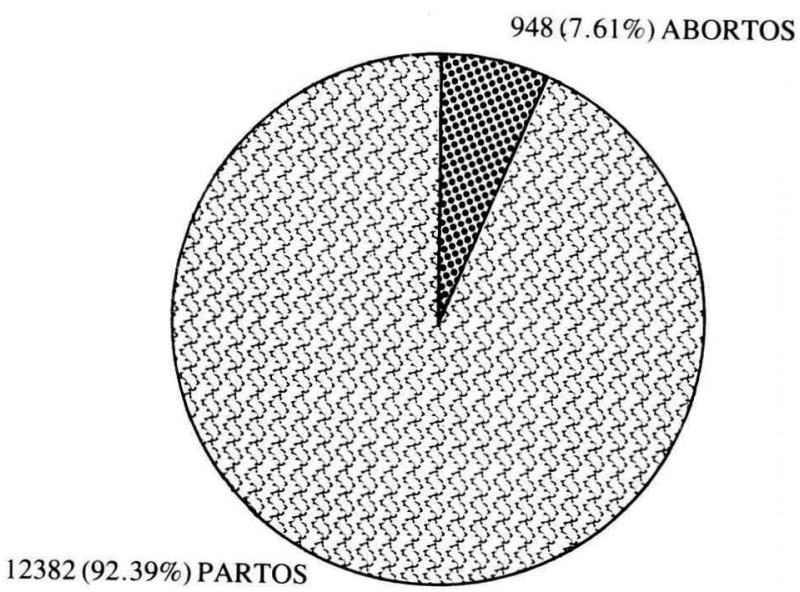

Figura 2

PORCENTANE DE ABORTOS CON RELACION A PARTOS (COLOMBIA)

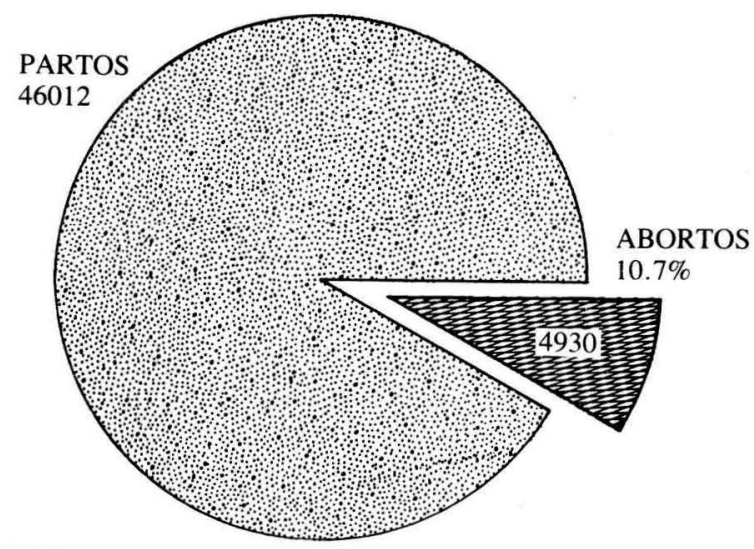

FECOLSOG 1990

Figura 3

PORCENTAJE DE ABORTOS CON RELACION A PARTOS (PERU)

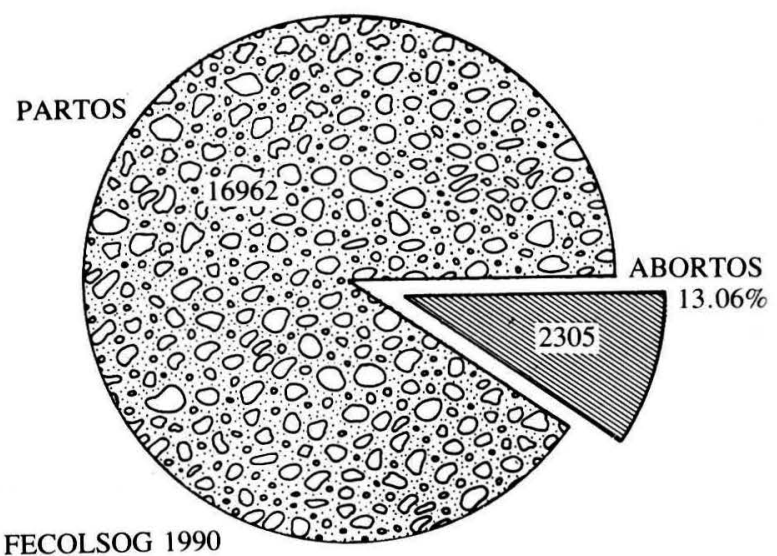


Figura 4

PORCENTAJE DE ABORTOS CON RELACION A PARTOS (VENEZUELA)

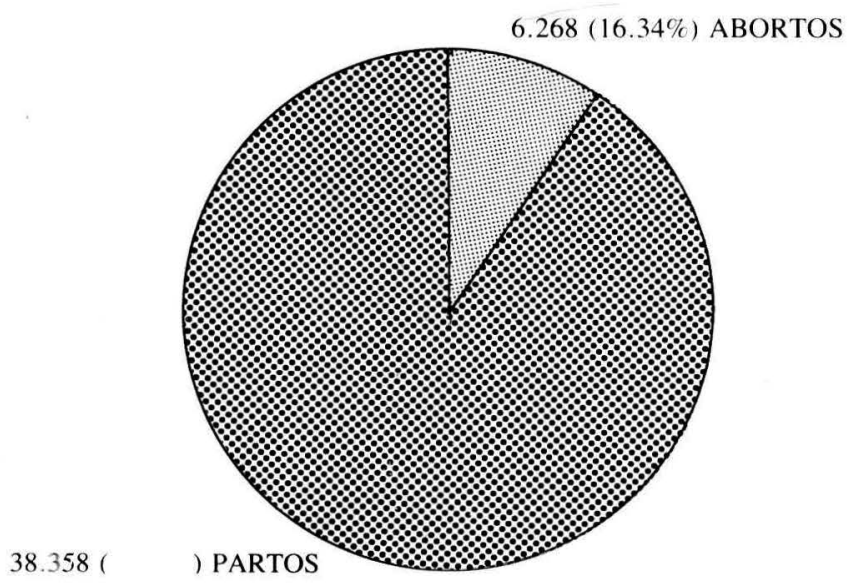

Figura 5

PORCENTAJE DE ABORTOS CON RELACION A PARTOS (BOLIVIA - COLOMBIA - PERU - VENEZUELA)

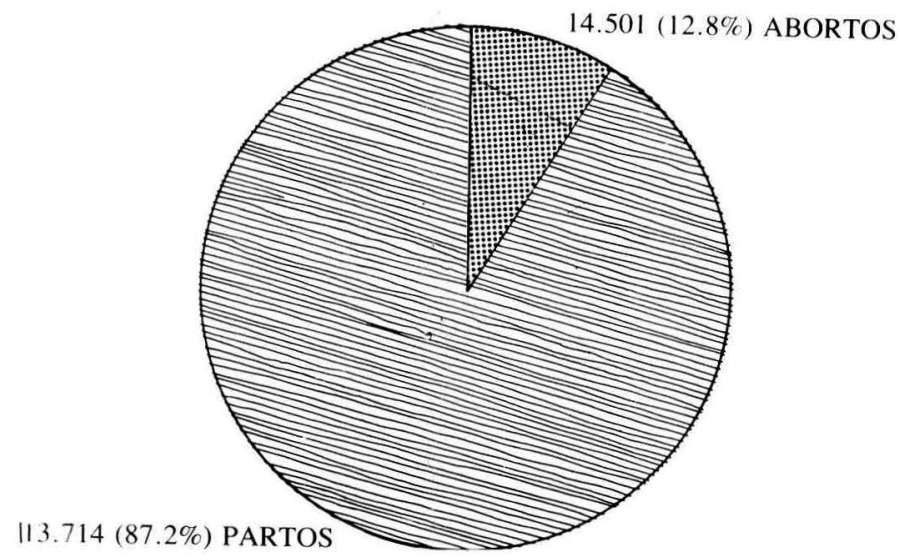

Tabla 1

INSTITUCIONES Y NUMERO DE CASOS POR PAIS

\begin{tabular}{|lccr|}
\hline País & No. Instituciones & No. Casos & $\%$. \\
\hline Bolivia & 5 & 783 & 8.83 \\
Colombia & 15 & 4.263 & 48.05 \\
Perú & 6 & 1.933 & 21.79 \\
Venezuela & 10 & 1.892 & 21.33 \\
\hline TOTAL & 36 & 8.871 & 100.00 \\
\hline
\end{tabular}

FECOLSOG 1990

$21.78 \%$ y mayo con $24.27 \%$ (Figura 6 ).

Edad de la paciente: El $13.47 \%$ son menores de 20 años, de las cuales $9.2 \%$ de los casos se presentaron en niñas adolescentes. La mayor incidencia se presentó en los grupos de 20 a 24 años, $27.38 \%$ y en el grupo de 25 a 29 años con el $25.65 \%$. El promedio de edad fue de 27.01 años (Figura 7).

Escolaridad de la paciente: $\mathrm{El}$ analfabetismo fue sólo en el $4.01 \%$ de las pacientes; la mayoría había cursado la primaria completa y la secundaria incompleta, con el $68.8 \%$ de las pacientes. La secundaria completa y la univer- sitaria la cursaron el $6.6 \%$; y las profesionales sólo fueron $0.4 \%$. El promedio de años de escolaridad fue de 6.95 años (Figura 8).

Número de embarazos previos: Cursaban su primer embarazo el $20.54 \%$ de las pacientes; la gran mayoría habían tenido uno o más embarazos previos casi el $80 \%$ de las

\section{ABORTOS SEGUN FECHA ADMISION}
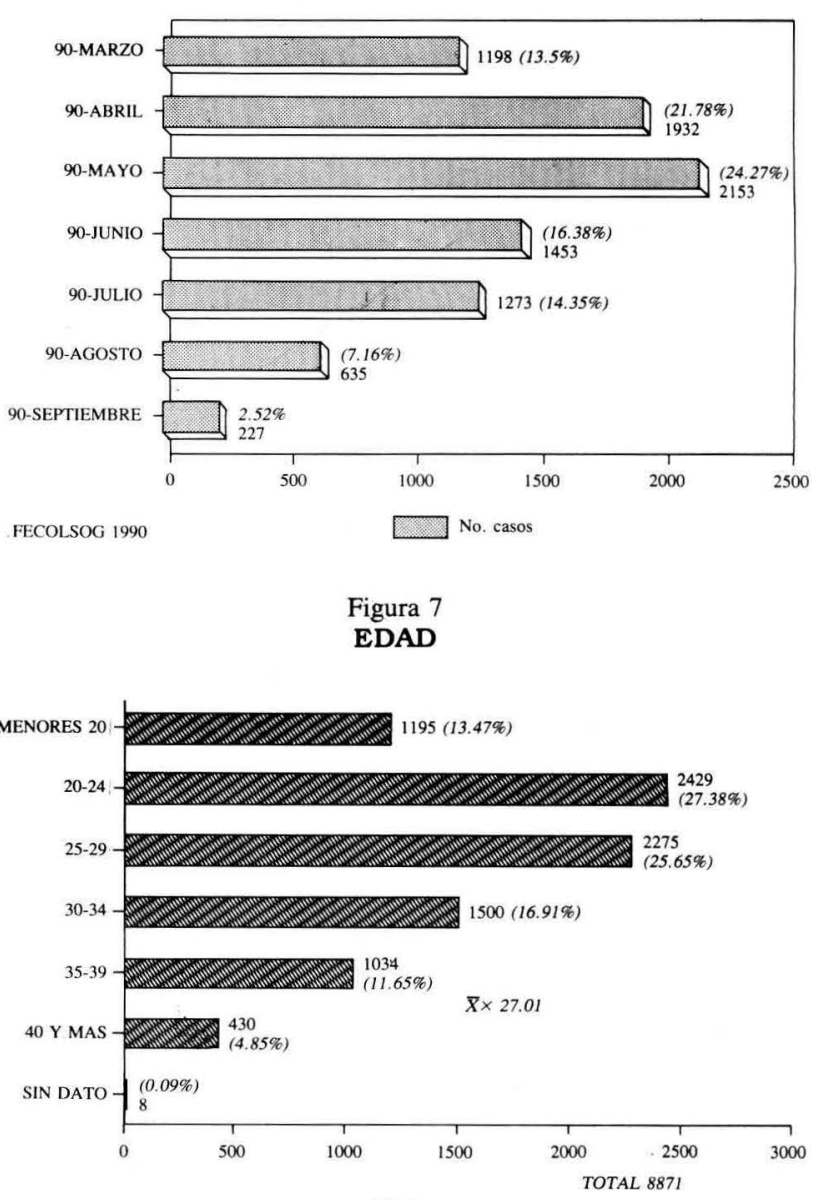

FECOLSOG 1990

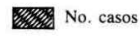

Figura 8

ESCOLARIDAD

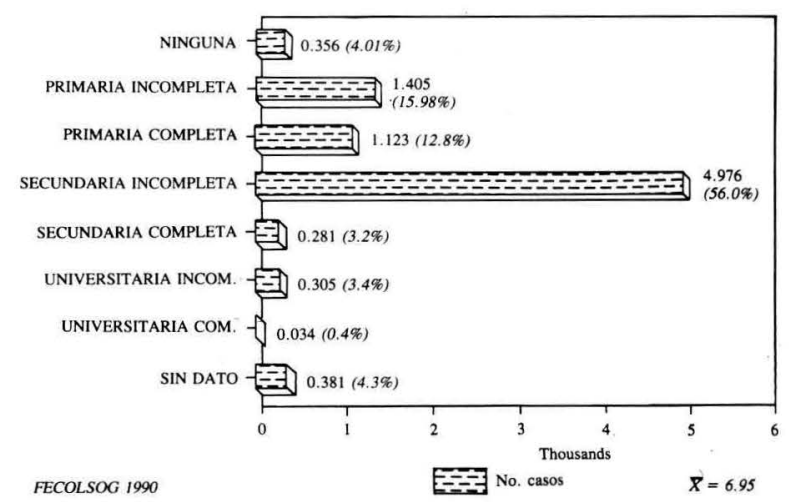


pacientes (79\%). El promedio fue de 2.48 embarazos previos (Figura 9).

Número de abortos previos: La mayoría de las pacientes no tenían abortos previos, $69.82 \%$; el $28.2 \%$ sí tenían este antecedente. El promedio fue de 0.43 abortos previos (Figura 10).

Estado marital: La gran mayoría, casi el $80 \%$ (78.94\%), tenían unión estable (Figura 11).

Embarazo actual deseable: En la mayoría de las pacientes, $51.98 \%$, el embarazo actual fue deseado. El $42.93 \%$ de las pacientes reconocieron que el embarazo actual fue indeseado (Figura 12).

Número adicional de hijos: El $51.84 \%$ de las pacientes informaron el deseo de tener hijos adicionales a los que ya tenían. Un porcentaje importante $41.61 \%$ no deseaban ningún hijo adicional. El promedio de hijos adicionales fue de 0.92 (Figura 13).

Anticonceptivo usado (en el mes cuando ocurrí el embarazo): La mayoría de las pacientes no utilizaban ningún método anticonceptivo, $69.62 \%$. El 9.49\% utilizaban métodos de baja efectividad lo que hace que la gran mayoría de las pacientes, casi el $80 \%$ (79.11\%), estuvieran altamente expuestas a un embarazo. El $15.52 \%$ de las pacientes utilizaban métodos anticonceptivos de alta efectividad (Figura 14).

Figura 9

\section{EMBARAZOS PREVIOS}
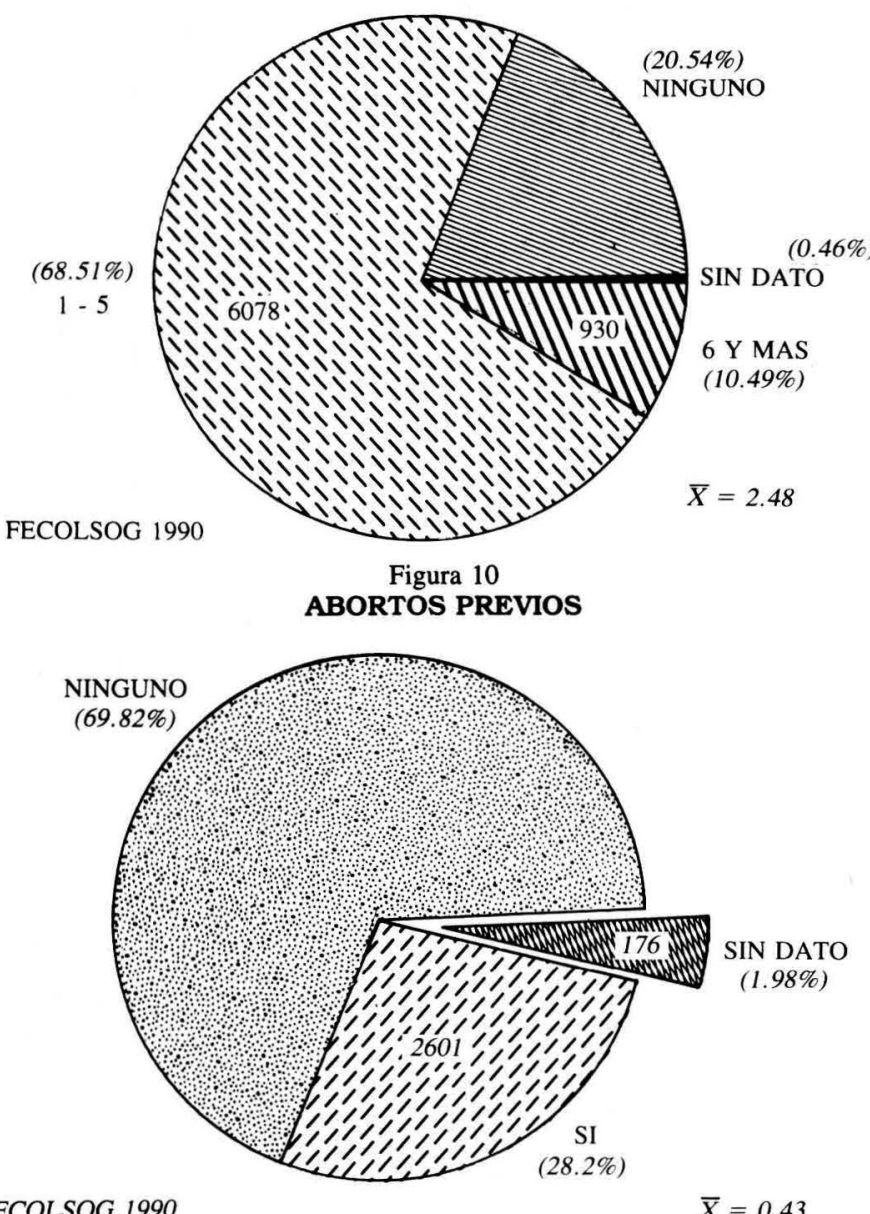

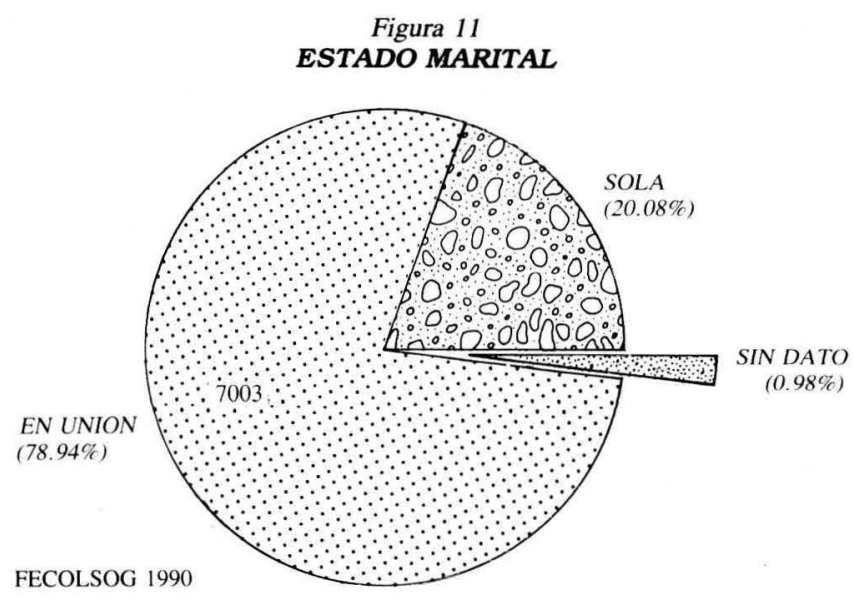

Figura 12

EMBARAZO ACTUAL DESEADO

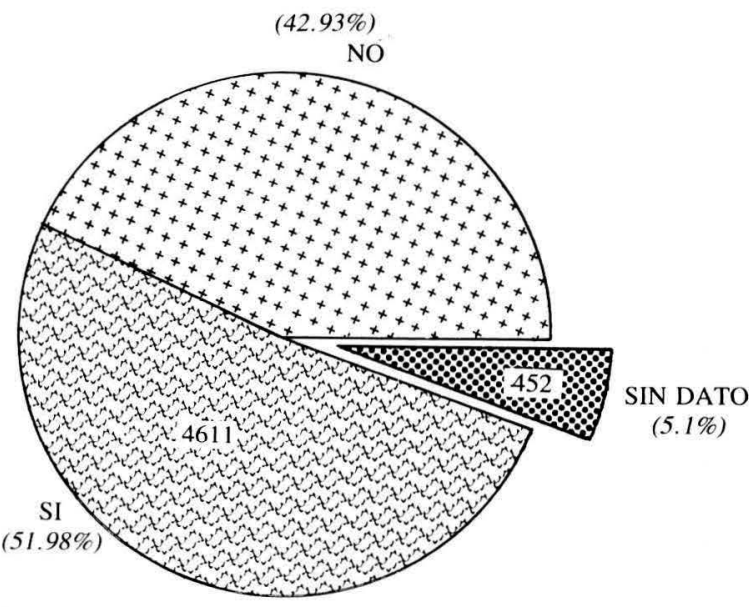

FECOLSOG 1990

Figura 13

DESEO ADICIONAL DE HIJOS

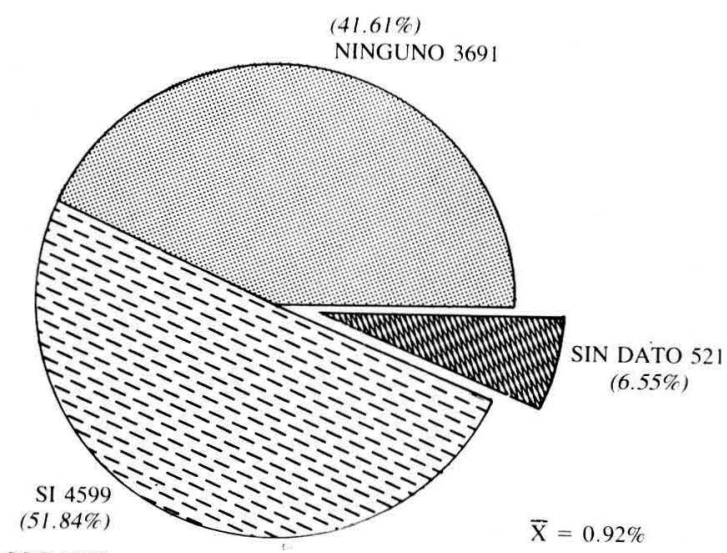

FECOLSOG 1990

Edad gestacional: Hasta 10 semanas de gestación fueron el $46.13 \%$ de las pacientes y con 11 y más semanas de gestación el $48.41 \%$. El promedio de semanas de gestación fue de 11.15 semanas (Figura 15). 
Figura 14

ANTICONCEPTIVO USADO

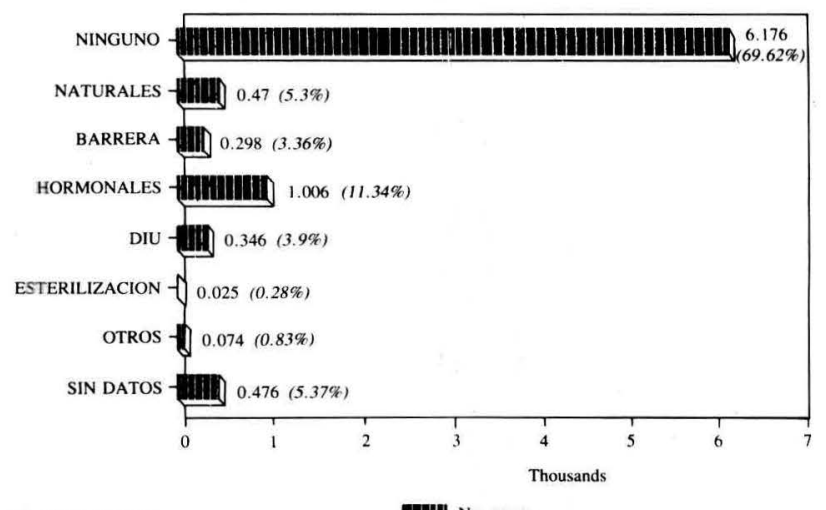

FECOLSOG 1990

Figura 15 EDAD GESTACIONAL

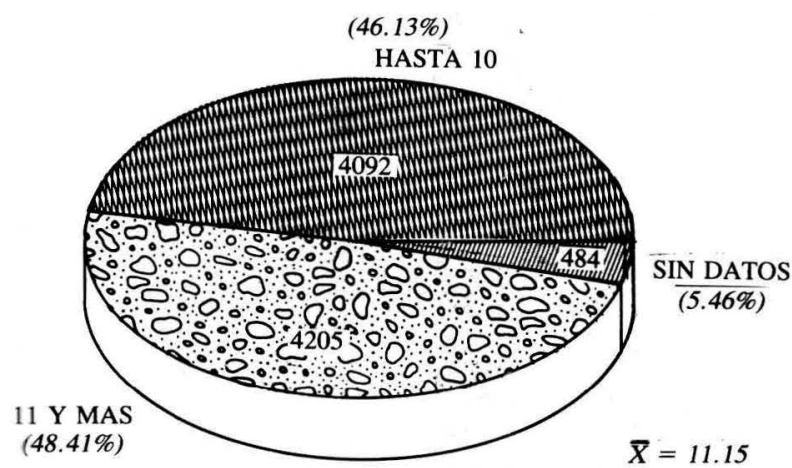

\section{FECOLSOG 1990}

Clasificación del aborto al ingreso (excepto sepsis): La mayoría de los abortos fueron incompletos al ingreso, $75.55 \%$ (Figura 16).

Aborto séptico al ingreso: En la mayoría de las pacientes el aborto no fue séptico, $84.44 \%$. En el $15.17 \%$ el aborto fue clasificado como séptico al ingreso (Figura 17).

Tipo de infección: La gran mayoría fue clasificada como endometritis, $83.12 \%$; presentaba un grado avanzado de infección el $16.88 \%$ (Figura 18).

Figura 16

CLASIFICACION DEL ABORTO AL INGRESO

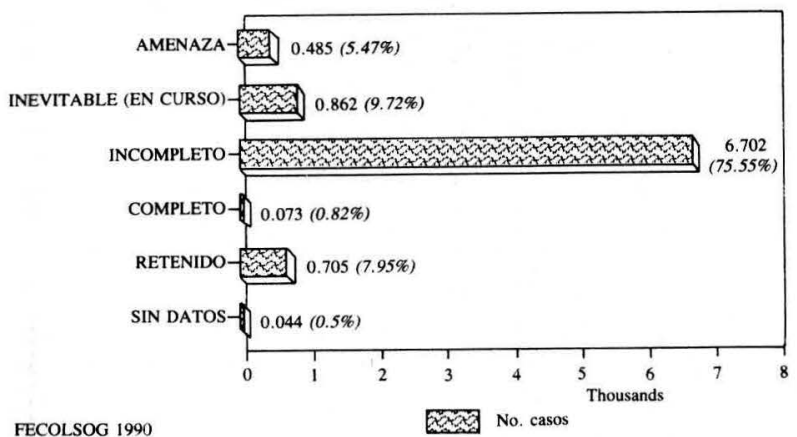

Fiebre en grados centígrados a la admisión: La gran mayoría de las pacientes, $75.25 \%$, no presentaban fiebre. Sólo el $13.07 \%$ sí presentaron fiebre al ingreso (Figura 19).

Tipo de aborto: En la gran mayoría de las pacientes el aborto fue espontáneo, $85.12 \%$. Sólo lo reconocieron como provocado el $11.59 \%$ (Figura 20).

Complicación al ingreso: La gran mayoría de las pacientes no presentaban complicación al ingreso, 88.87\%. Sólo presentaron complicación al ingreso el 9.05\% (Figura 21).
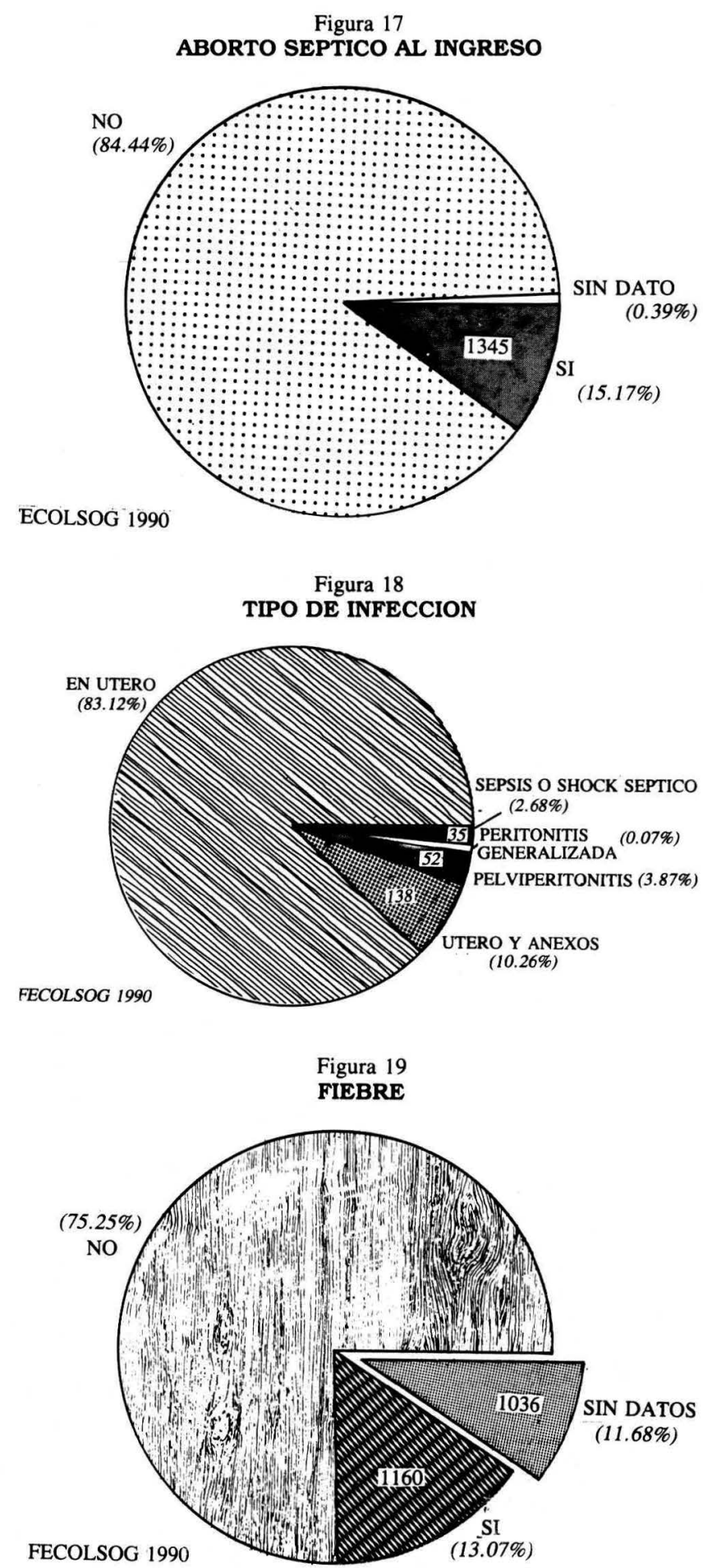
Figura 20

TIPO DE ABORTO

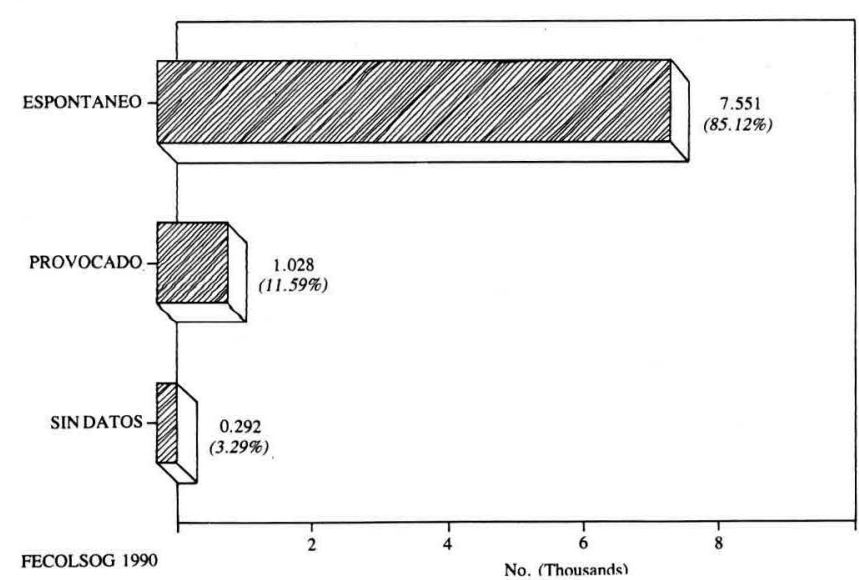

Figura 21

COMPLICACION AL INGRESO

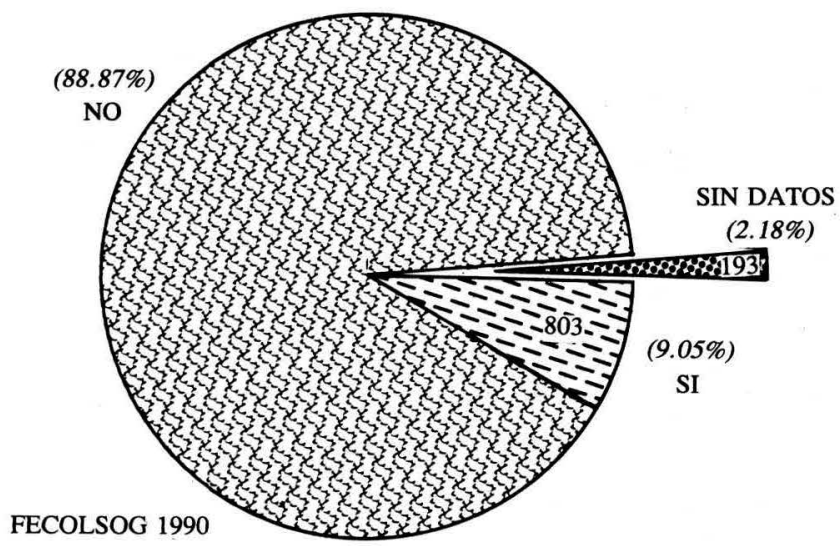

Figura 22

TIPO DE COMPLICACION AL INGRESO

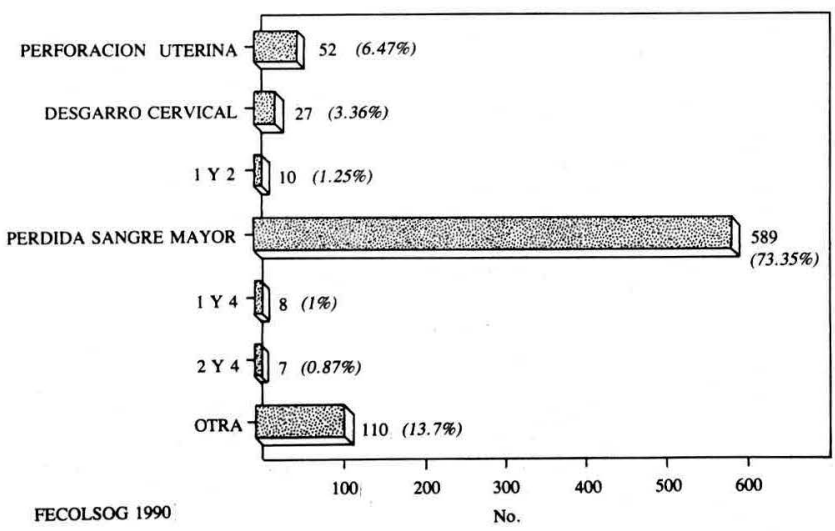

Tipo de complicación al ingreso: La principal complicación al ingreso fue la pérdida excesiva de sangre, $73.35 \%$, seguida de la perforación uterina con $6.47 \%$ (Figura 22).

Procedimiento hospitalario para evacuar el útero: En la gran mayoría se utilizó el legrado uterino, $94.76 \%$. Sólo se utilizó otro procedimiento en el $2.37 \%$ (Figura 23).
Anestesia: En la mayoría de los casos se utilizó la anestesia general, $65.48 \%$, seguida por otro tipo de anestesia no especificada en el $25.66 \%$ (Figura 24)

Transfusión: La gran mayoría de las pacientes no requirieron transfusión, $94.3 \%$. De las 521 pacientes que requirieron transfusión $(5.87 \%)$ el promedio por paciente fue de 921 centímetros cúbicos (Figura 25).

Figura 23

PROCEDIMIENTO HOSPITALARIO

PARA EVACUAR UTERO

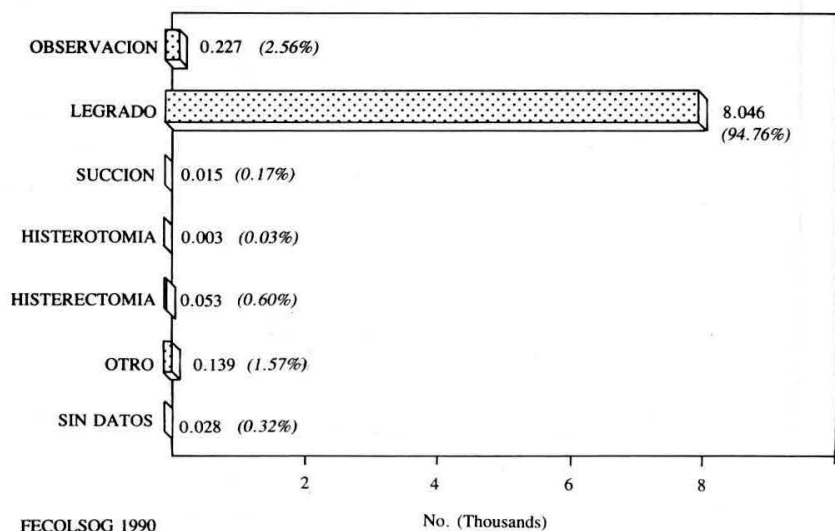

Figura 24

ANESTESIA

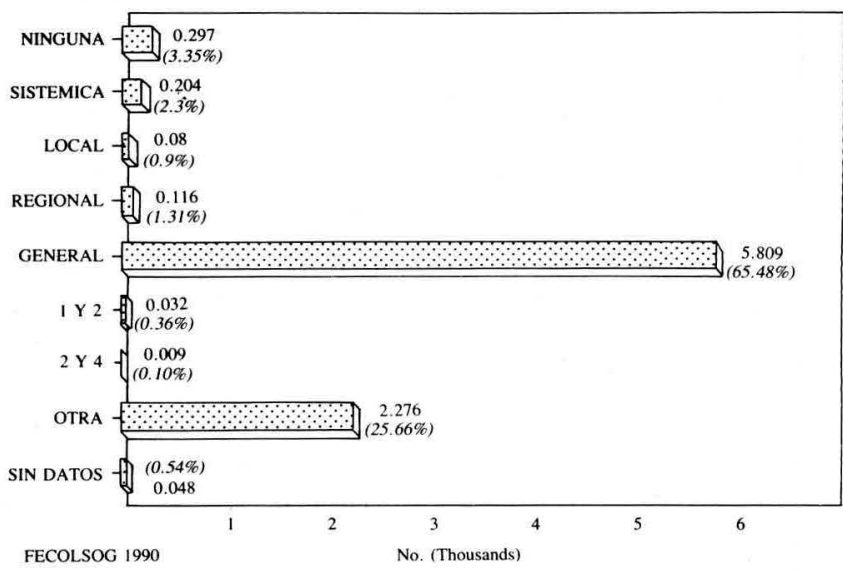

Figura 25

TRANSFUSION

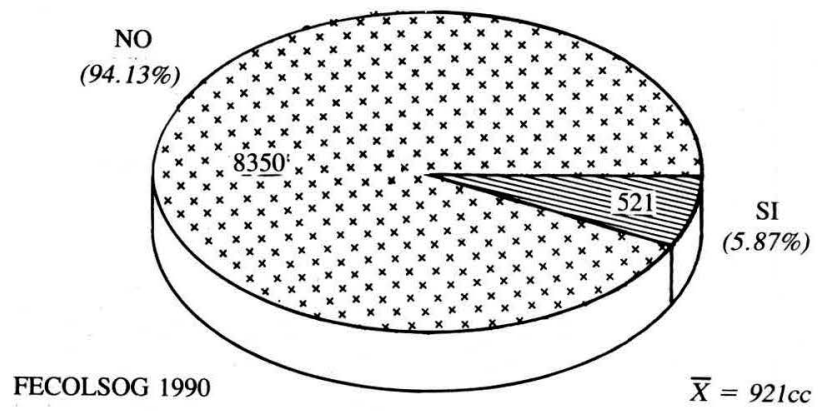


Líquidos intravenosos: La gran mayoría de las pacientes recibieron líquidos intravenosos, $84.88 \%$. Sólo el $15.12 \%$ no requirieron infusiones intravenosos (Figura 26).

Procedimiento quirúrgico adicional: De las pacientes que requirieron otro procedimiento adicional al legrado uterino en su mayoría este método fue la histerectomia, 32.09\% (Figura 27).

Muerte materna: En la gran mayoría de las pacientes no se presentó muerte, $98.97 \%$. La muerte materna se presentó en el $0.35 \%$ de las pacientes (Figura 28).

Tasa de mortalidad por aborto: En los 8.871 casos analizados se presentaron 36 muertes que de una tasa de mortalidad por aborto de $406 \times 100.000$ (Figura 29). En la Tabla 2 se pueden ver las tasas de mortalidad comparativas por país.

Anticonceptivo prescrito al alta: En la gran mayoría de las pacientes, $60.48 \%$, no se previó ningún método anticonceptivo al darles de alta. Sólo el $36.62 \%$ salió con fórmula de anticoncepción (Figura 30).

Número de noches hospitalizada: La mayoría de las pacientes permanecieron más de una noche $44.05 \%$. Una noche el $39.98 \%$ y ninguna noche $13.63 \%$. El promedio de estancia hospitalaria fue de 1.8 noches (Figura 31 ).

Edad gestacional según estancia: En los embarazos de menos de 10 semanas la mayoría de las pacientes no permanecieron ninguna noche en el hospital, 53.92\%,

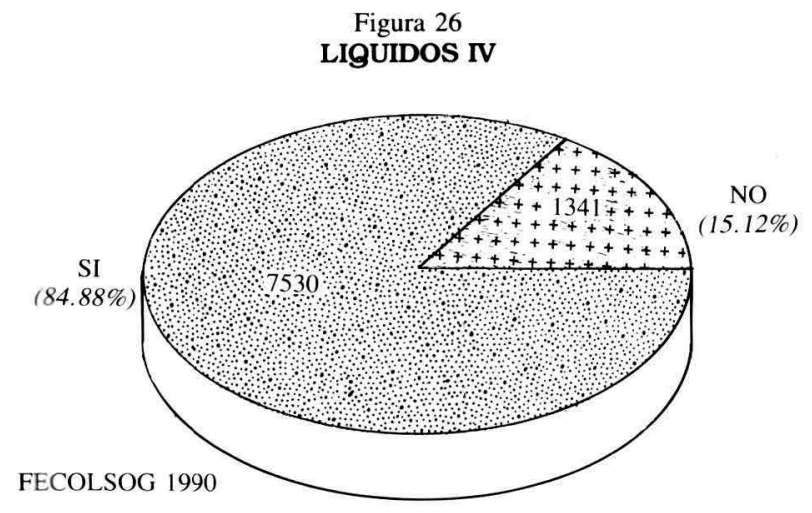

Figura 27 TIPO PROCEDIMIENTO QUIRURGICO ADICIONAL

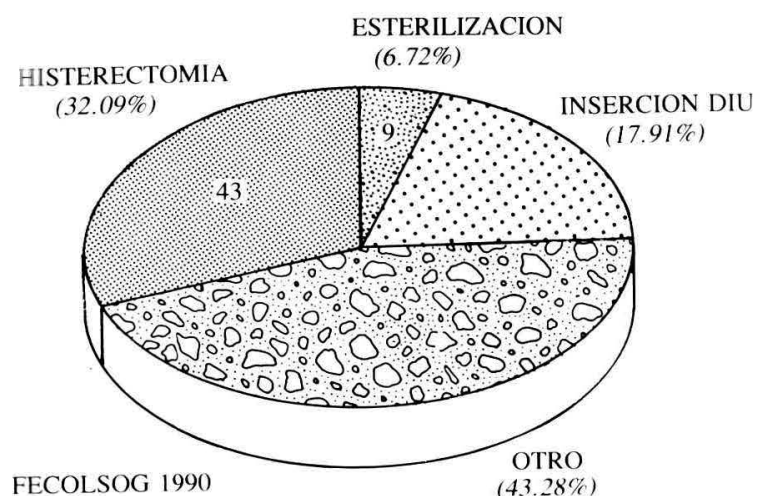

FECOLSOG 1990

$(4.28 \%)$
Figura 28

MUERTE MATERNA

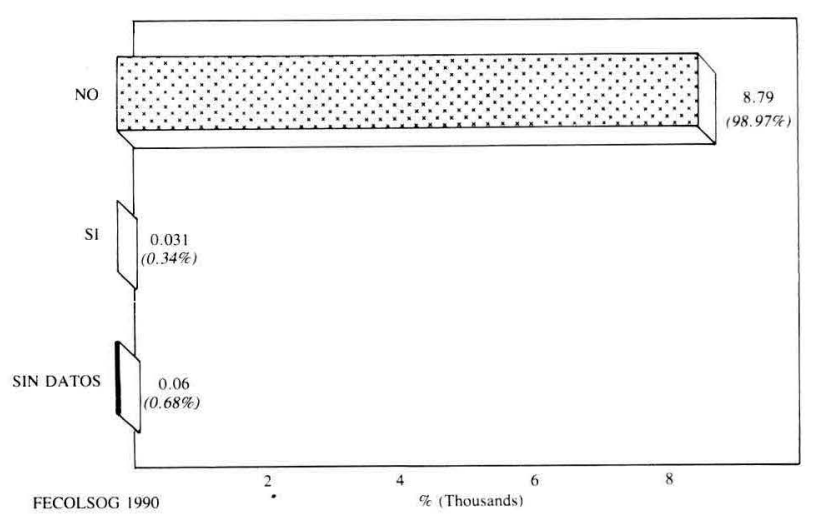

Figura 29

$$
\begin{gathered}
\text { TMM } \times \text { ABORTO }=\frac{36}{8871} \times 100.000= \\
406 \times 100.0000
\end{gathered}
$$

FECOLSOG 1990

Tabla 2

TASAS DE MORTALIDAD $\times 100.000$ COMPARATIVAS POR PAIS

\begin{tabular}{|lccr|}
\hline \multicolumn{1}{|c}{ País } & No. Muertes & No. Abortos & Tasa \\
\hline Bolivia & 8 & 783 & 1022 \\
Colombia & 21 & 4263 & 493 \\
Perú & 6 & 1933 & 310 \\
Venezuela & 1 & 1892 & 53 \\
\hline TOTAL & 36 & 8871 & 406 \\
\hline
\end{tabular}

FECOLSOG 1990

mientras que en las gestaciones de 11 y más semanas la mayoría de las pacientes permanecieron dos o más noches, $54.41 \%$ (Tabla 3 ).

Muerte materna según duración del embarazo: De las 36 pacientes que presentaron muerte materna la mayoría, 22 casos $(61.10 \%$ ), cursaban 11 o más semanas de gestación (Tabla 4).

Muerte materna según diagnóstico del aborto al ingreso: De las 36 pacientes que presentaron muerte materna la gran mayoría, 25 casos (69.40\%), el aborto fue clasificado como incompleto al ingreso (Tabla 5).

Muerte materna según aborto séptico al ingreso: De las 36 muertes maternas la gran mayoría, 27 casos (75\%), el aborto fue clasificado como séptico al ingreso (Tabla 6).

Muerte según complicación al ingreso excepto sepsis: De las 36 muertes cuando no se toma en cuenta la sepsis como complicación al ingreso, 20 pacientes (55.60\%) aparecen sin ninguna complicación; 8 (22.2\%) con otra complicación no clasificada; $4(11.1 \%)$ hemorragia profusa, y $4(11.1 \%)$ perforación (Tabla 7$)$. 
Figura 30

ANTICONCEPTIVO PRESCRITO

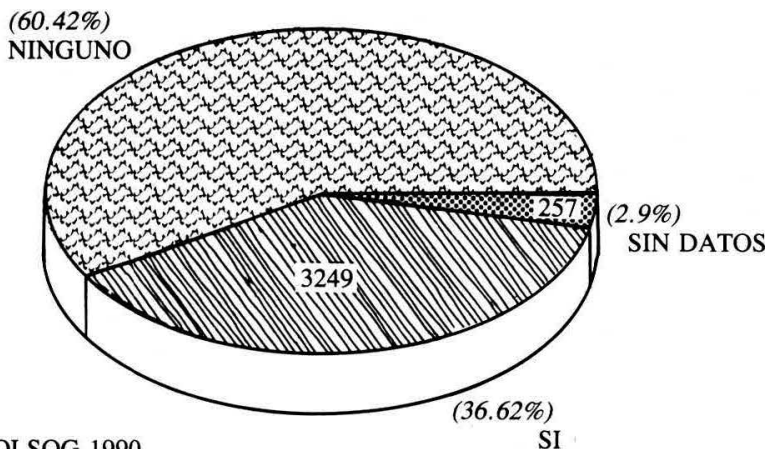

FECOLSOG 1990

Figura 31

NUMERO DE NOCHES HOSPITALIZADA

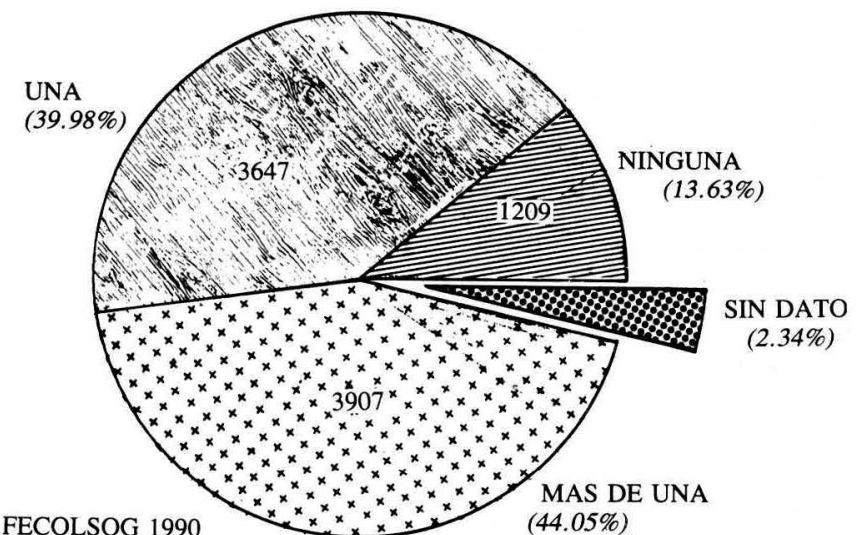

$$
\bar{X}=1.8
$$

Tabla 3

EDAD GESTACIONAL SEGUN ESTANCIA

\begin{tabular}{|lcccc|}
\hline $\begin{array}{l}\text { Edad } \\
\text { gestacional }\end{array}$ & \multicolumn{4}{c}{ Estancia hospitalaria } \\
Ninguna & Una & Más de una & Total \\
\hline Hasta 10 & 633 & 1692 & 1676 & 4001 \\
& $(53.92 \%)$ & $(50.48 \%)$ & $(45.59 \%)$ & $(48.78 \%)$ \\
11 y más & 541 & 1660 & 2000 & 4201 \\
& $(46.08 \%)$ & $(49.52 \%)$ & $(54.41 \%)$ & $(51.22 \%)$ \\
\hline TOTAL & 1174 & 3352 & 3676 & 8202 \\
& $(100 \%)$ & $(100 \%)$ & $(100 \%)$ & $(100 \%)$ \\
\hline
\end{tabular}

FECOLSOG 1990

Tabla 4

MUERTE MATERNA SEGUN DURACION EMBARAZO

\begin{tabular}{|c|c|c|c|}
\hline \multirow{2}{*}{$\begin{array}{l}\text { Muerte } \\
\text { materna }\end{array}$} & \multicolumn{2}{|c|}{ Duración del embarazo } & \multirow[b]{2}{*}{ Total } \\
\hline & Hasta 10 & 11 y más & \\
\hline No & $4059(48.87 \%)$ & $4247(51.13 \%)$ & $8306(100 \%)$ \\
\hline $\mathrm{Si}$ & $14(38.90 \%)$ & $22(61.10 \%)$ & $36(100 \%)$ \\
\hline
\end{tabular}

FECOLSOG 1990
Tabla 5

MUERTE MATERNA SEGUN DX ABORTO INGRESO

\begin{tabular}{|lcccccc|}
\hline $\begin{array}{l}\text { Muerte } \\
\text { materna }\end{array}$ & Amén & Curso & Incom. & Comp. & Ret. & Total \\
\hline No & 471 & 857 & 6642 & 70 & 700 & 8740 \\
& $(5.39 \%)$ & $(9.81 \%)$ & $(76 \%)$ & $(0.8 \%)$ & $(8 \%)$ & $(100 \%)$ \\
$\mathrm{Si}$ & 5 & 1 & 25 & 3 & 2 & 36 \\
& $(13.9 \%)$ & $(2.8 \%)$ & $(69.4 \%)$ & $(8.3 \%)$ & $(5.6 \%)$ & $(100 \%)$ \\
\hline
\end{tabular}

FECOLSOG 1990

Tabla 6

MUERTE MATERNA SEGUN ABORTO SEPTICO AL INGRESO

\begin{tabular}{|lrrr|}
\hline $\begin{array}{l}\text { Muerte } \\
\text { materna }\end{array}$ & \multicolumn{3}{c|}{ Aborto séptico } \\
No & \multicolumn{1}{c|}{ Si } & \multicolumn{1}{c|}{ Total } \\
\hline $\mathrm{No}$ & $7432(84.92 \%)$ & $1320(15.08 \%)$ & $8752(100 \%)$ \\
$\mathrm{Si}$ & $9(25.00 \%)$ & $27(75.00 \%)$ & $36(100 \%)$ \\
\hline
\end{tabular}

FECOLSOG 1990

Tabla 7

MUERTE MATERNA SEGUN COMPLICACION AL INGRESO (EXCEPTO SEPSIS)

\begin{tabular}{|lcccccc|}
\hline Muerte & \multicolumn{6}{c|}{ Complicación al ingreso } \\
materna & No & Perf. & DC & Hemo & Otra & Total \\
\hline No & 7819 & 66 & 34 & 583 & 102 & 8604 \\
& $(90.88 \%)$ & $(0.77 \%)$ & $(0.39 \%)$ & $(6.78 \%)$ & $(1.18 \%)$ & $(100 \%)$ \\
$\mathrm{Si}$ & 20 & 4 & 0 & 4 & 8 & 36 \\
& $(55.6 \%)$ & $(11.1 \%)$ & & $(11.1 \%)$ & $(22.2 \%)$ & $(100 \%)$ \\
\hline
\end{tabular}

FECOLSOG 1990

\section{Discusión de resultados}

La frecuencia de abortos osciló mucho durante los diferentes meses del estudio, sin que se pueda establecer ningún patrón; intervinieron como factores las huelgas que impidieron la recolección durante seis meses completos en algunas instituciones y en los meses de marzo y septiembre durante los cuales sólo se recolectó información en la última quincena de marzo y primera quincena de septiembre. El porcentaje de abortos con relación a partos de $12.8 \%$ es mayor, ya que no se tiene seguridad absoluta sobre el número de abortos ocurridos (Figura 5).

La población del estudio es de mujeres jóvenes siendo en su mayoría, $62.08 \%$, menores de 29 años con un promedion de 27.01 años (Figura 7).

El analfabetismo es bajo sólo $4.01 \%$ de pacientes y mucho más bajo el nivel profesional de sólo $0.4 \%$. Es importante hacer notar que la gran mayoría, $91.29 \%$ tenían algún nivel de escolaridad. El bajo porcentaje de pacientes con secundaria completa o estudios universitarios se explica, por el tipo de instituciones que hacen parte del estudio, que son todas instituciones que no atienden un nivel socioeconómico alto como son las clínicas privadas (Figura 8).

Sólo cursaban su primer embarazo el $20.54 \%$ de las pacientes, la gran mayoría, 79\%, tenían uno o más embarazos previos. Siendo una población joven el porcentaje de pacientes con más de un embarazo es importante (Figura 9). 
A pesar de que la mayoría de las pacientes no tenían abortos previos, $69.82 \%$, es notable que para una población con promedio de edad de 27.01 años y con $62.08 \%$ de menores de 28 casi el $30 \%$ de ellas $(28.2 \%)$ ya tenían como antecedente uno o más abortos (Figura 10).

Aun cuando en la mayoría de las pacientes el embarazo actual fue deseado, $51.98 \%$, un porcentaje muy importante de pacientes, $42.93 \%$, respondieron que no deseaban el embarazo (Figura 12); que además coincide con el $41.61 \%$ de pacientes que manifestaron no querer ningún otro hijo adicional a los que actualmente tenían (Figura 13); y contrasta con el bajo porcentaje de mujeres que aceptaron que el aborto actual fue provocado (11.59\%). Es muy llamativo que casi el $70 \%$ de las pacientes $(69.62 \%)$ no utilizaran ningún método anticonceptivo y el $9.49 \%$ estaban utilizando métodos de muy baja efectividad, lo que suma casi el $80 \%$ (79.11\%) de pacientes que estaban altamente expuestas al embarazo. La falla de métodos de alta efectividad como la píldora, que la usaban $9.5 \%$ de pacientes, puede explicarse en que este método exige una alta motivación y un gran cuidado en su uso correcto.

Uno de los factores que seguramente incide en la alta tasa de mortalidad por aborto encontrada en el estudio puede ser el alto porcentaje, $48.41 \%$, de abortos tardíos (11 y más semanas de gestación) (Figura 15).

El gran porcentaje de abortos incompletos al ingreso, $75.55 \%$, puede estar relacionado con la complicación más frecuente encontrada que fue la hemorragia profusa (73.35\%) que a su vez está relacionada con la cantidad de líquidos intravenosos que en promedio fue de 1.945 centímetros cúbicos (Gráfico 21), y con la cantidad de sangre transfundida que en las pacientes que lo requirieron hubo un promedio de 921 centímetros cúbicos (Figura 16).

En una población joven con promedio de edad de 27.01 años, el que se les haya realizado a 43 pacientes histerectomia indica la grave morbilidad a que el aborto expone a la población materna (Figura 27).

La tasa de mortalidad por aborto de $406 \times 100.000$ (Figura 29) es muy alta comparada con la mortalidad materna para Latinoamérica que en un estudio publicado en 1987 de una tasa de $270 \times 100.000$ (3); y muy superior a la de 232 $\times 100.000$ de un estudio colombiano (4). Si se compara esta tasa de mortalidad por aborto de $349 \times 100.000$ con cifras mundiales que dan una tasa de mortalidad por aborto legal en el primer trimestre de gestación de $1.7 \times 100.000$ por parto de $14.1 \times 100.000$ y todavía muy superior a tasas de procedimientos riesgosos como la histerectomía con una cifra de $204 \times 100.000$; según el informe de población número 3 de marzo de 1976 de la George Washington University Medical Center (5).

La baja prescripción de métodos anticonceptivos al egreso (36.62\%) después de que una paciente ha pasado por una situación como el aborto, es preocupante (Figura 30) y lo es más si vemos que a través de los años esta situación no ha variado; incluso es peor si lo comparamos con un estudio que sobre aborto se hizo en hospitales universitarios de Colombia en 1975 cuando la prescripción de métodos anticonceptivos al egreso fue superior (46.1\%) (6).

El que la mayoría de los pacientes, $44.05 \%$, permanecieran más de una noche en el hospital, tiene incidencia en un mayor costo para las instituciones y las pacientes (Figura 31).

Analizando los cruces de variables observamos que entre más avanzada sea la gestación cuando ocurre el aborto, el número de noches de permanencia hospitalaria aumenta contribuyendo a un aumento en el costo institucional y social (Tabla 3). En la misma forma cuanto más avanzado sea el embarazo, cuando ocurre el aborto es mayor la probabilidad de muerte materna (Tabla 4).

Se encontró una mayor mortalidad cuando el aborto fue clasificado como incompleto al ingreso (Tabla 5), puede estar relacionado con la complicación más frecuente que fue la pérdida excesiva de sangre (Figura 22).

A pesar de que la complicación más frecuente al ingreso fue la pérdida excesiva de sangre (Figura 22), al cruzar la variable muerte con la sepsis al ingreso fue precisamente esta complicación la que tuvo una relación mayor con la muerte de la abortante (Tabla 6). Este hallazgo es similar al de varios estudios que sobre mortalidad materna se realizaron hace varios años en Colombia $(4,7,8,9,10,11)$. $\mathrm{La}$ anterior afirmación se confirma al cruzar la variable complicación al ingreso excluyendo la sepsis en la cual la hemorragia profusa ocupa el tercer lugar y está relacionada con la muerte materna sólo en el $12.9 \%$ (Tabla 7).

\section{Conclusiones}

- La población de mujeres del estudio es joven, con un promedio de 27.01 años.

- El analfabetismo fue bajo y la mayoría de las pacientes habían cursado uno o más años de escolaridad.

- En casi la mitad de las pacientes el embarazo fue indeseado.

- Casi la mitad de las pacientes no deseaban ningún hijo adicional al que tenían.

- La mayoría de las pacientes no utilizaban ningún método anticonceptivo o utilizaban métodos de baja efectividad. A la mayoría no se les prescribió ningún anticonceptivo al egreso.

- La mitad de los casos cursaban 11 semanas o más de gestación.

- La complicación infecciosa más frecuente fue la endometriosis.

- En la mayoría de las pacientes el aborto fue clasificado como incompleto al ingreso.

- La complicación al ingreso más frecuente fue la pérdida excesiva de sangre.

- La tasa de mortalidad por aborto $(406 \times 100.000)$ es el doble de la mortalidad materna para la región.

- La sepsis fue la complicación más relacionada con la muerte materna.

- Los costos que demandó la atención de las pacientes se vieron incrementados por el elevado requerimiento.de: líquidos intravenosos, sangre, anestesia general y estancia hospitalaria.

\section{Recomendaciones}

El bajo uso de métodos anticonceptivos sumado al alto porcentaje de pacientes que reconocieron que el embarazo actual fue indeseado y a la mayoría de las pacientes que no querían ningún hijo adicional al que actualmente tenían, hace suponer que a pesar de que no lo reconozcan, la mayoría 
de los abortos posiblemente fueron provocados.

La alta tasa de mortalidad por aborto y la sepsis como complicación más relacionada con la muerte materna, hace suponer que estos abortos en su mayoría fueron provocados y realizados en condiciones de inseguridad.

El grupo de investigadores ante estos hallazgos se permite hacer las siguientes recomendaciones:

- Mejorar el conocimiento y la accesibilidad de los métodos anticonceptivos para así reducir el número de mujeres expuestas al riesgo de un embarazo indeseado.

- Aumentar, promover y en algunos casos incluir la educación sexual en todas las instituciones docentes desde los colegios hasta las universidades.

- Interesar a las instituciones públicas y privadas responsables de programas docentes y asistenciales, en la implemen- tación de las recomendaciones anteriores, pues del análisis comparativo con investigaciones sobre el tema, realizadas hace 15 o más años en la región, se evidencia que la situación, lejos de mejorar, está igual y en algunos casos peor.

\section{Agradecimientos}

A la Jessie Smith Noyes Foundation por la donación otorgada a la investigación.

A todos y cada uno de los coordinadores nacionales e institucionales ya que sin su colaboración en la recolección de la información no hubiese sido posible realizar la presente investigación.

\section{BIBLIOGRAFIA}

1. Pardo Francisco, Uriza Germán. "Estudio de Embarazo en Adolescentes en 11 Instituciones Colombianas", Bogotá, 1989 (para publicación No. 2 del Vol. 42 de la Revista Colomhiana de Obstetricia y Ginecología, 1991).

2. Conferencia Internacional sobre Maternidad sin Riesgo. Nairobi, Kenya, febrero 1987. World Bank, W.H.O., UNFPA, pág. 6.

3. Family Health International: "Maternal Mortality is Global Problem". Network 1987; 9(1).

4. Uriza Germán, López Guillermo, Riaño Germán, Estrada Alcides. “Estudio Hospitalario de Mortalidad Materna”. Rev Col Obstet Ginecol $1982 ; 33(5)$

5. López Guillermo, Riaño Germán, Lenis Nelson. “Aborto”, Monografías de la Corporación Centro Regional de Población 1987; 8: 22.

6. Riaño Germán, Ferguson James, Goldsmith Alfredo. "Manejo Clínico del Aborto Incompleto en los Hospitales Universitarios de Co- lombia”. Asociación Colombiana de Facultades de Medicina, pág. $11,1979$.

7. Rojas Laura, Ramírez Rafael, Cantillo Jaime. "Morbilidad Materna en el Instituto Materno Infantil de Bogotá, Colombia”. Rev Col Obstet Ginecol 1974; 25(2)

8. Sánchez T Fernando. "Mortalidad Materna en el Instituto Materno Infantil de Bogotá, 1971-1973”. Rev Col Obstet Ginecol 1974; 25(6).

9. Jubiz H Alfonso, Sánchez M Carmen. "Mortalidad Materna Comparativa entre Dos Períodos 1963-1967, 1968-1972”. Rev Col Obstet Ginecol 1976; 27(3).

10. Sánchez T Fernando. "Mortalidad Materna”. Rev Col Obstet Ginecol 1977; 28(6).

11. Jubiz H Alfonso, Sánchez M Carmen. "Muertes Maternas en el Hospital San Vicente de Paúl". Rev Col Obstet Ginecol 1978; 29(4).

\section{* investigadores}

Director del Estudio: FRANCISCO PARDO

Investigador Principal: GERMAN URIZA

\section{COORDINADORES NACIONALES}

BOLIVIA JOSE LARREA

COLOMBIA GERMAN URIZA

PERU LUIS TANG

VENEZUELA ORLANDO GUTIERREZ

COORDINADORES INSTITUCIONALES DE COLOMBIA

DARIO ZAPATA

VICTOR RODRIGUEZ

LUIS ALFONSO LOPEZ

ARMANDO LOZANO

LUES F. CASTAÑO

JAIRO DE LA CRUZ

HERNANDO RUIZ

GERMAN BARON

MIGUEL RODRIGUEZ

OSCAR GOMEZ

RAUL VARGAS

HERNANDO NAVARRO

EMILIO ESCALANTE

JOSE CAICEDO
GERMAN PLAZA

GUILLERMO ARBOLEDA

COORDINADORES INSTITUCIONALES DE PERU

LUIS TANG(Hijo)

AUGUSTO CAM

FERNANDO LEON

ROBERTO RODRIGUEZ
COORDINADORES INSTITUCIONALES DE VENEZUELA

CARMEN PEREZ

YARITZA LOPEZ

MIREYA GONZALEZ

MARY VALERA

CORALIA GONZALEZ

OFELIA UZCATEGUI

CLAMBEL DICURU

MARIA PILAR ALONSO

ALEX PINZON

CARMEN AFONSO

FELIX PEÑA

MENPHIS BELLORIN
MARIA E. MENDOZA

MAURA ORTEGA

YAJAIRA COROMOTO

J.R. LOPEZ

GASTON MAURE

ALBERTO MOLINA

HERNAN GONZALEZ

RUBEN RAGARDIZ

HENDER BOSCAN

MANUEL SILVA

JULIO ESPINOZA 